\title{
Synthesis and Properties of
}

\section{(3-Phenyl-1-azulenyl)tetracyanobetadienes and Tris(aryltetracyanobetadiene)s Connected with}

\section{1,3,5-Tri(1-azulenyl)benzene Core}

\author{
Taku Shoji, ${ }^{* a, b]}$ Akifumi Maruyama,${ }^{[b]}$ Miwa Tanaka, ${ }^{[a]}$ Daichi Nagai, ${ }^{[b]}$ Erika Shimomura,${ }^{[a]}$ Kunihide \\ Fujimori, ${ }^{[\mathrm{a}]}$ Shunji Ito, ${ }^{[\mathrm{cc}]}$ Tetsuo Okujima, ${ }^{[\mathrm{d}]}$ Kozo Toyota, ${ }^{[\mathrm{e}]}$ and Masafumi Yasunami (the late $)^{[\mathrm{fl}}$
}

\begin{abstract}
Tris[(3-phenyl-1-azulenyl)tetracyanobutadiene]s and tris(aryltetracyanobutadiene)s connected to a 1,3,5-tri(1-azulenyl)benzene core (tris-AzTCBDs) have been prepared by the Pd-catalyzed alkynylation of tris(3-iodo-1-azulenyl)benzene derivative with the corresponding 1-ethynylazulene or ethynylbenzene derivatives under SonogashiraHagihara cross-coupling conditions, followed by the reaction with tetracyanoethylene (TCNE) in a formal [2 + 2] cycloadditionretroelectrocyclization (CA-RE) reaction. The intramolecular charge-transfer (ICT) interactions of the new chromophores were investigated by the comparison with those of the model tetracyanobutadiene derivatives with azulene substituents (AzTCBDs), which were prepared by the reaction of the corresponding 1-ethynylazulene derivative with iodoarenes, followed by the CA-RE reaction with TCNE, utilizing UV/Vis spectroscopy and theoretical calculations. The redox behavior of the alkyne precursors and the tetracyanobutadiene derivatives was examined by cyclic voltammetry $(\mathrm{CV})$ and differential pulse voltammetry (DPV), which revealed their multistep electrochemical reduction properties. Moreover, significant color changes of these compounds were
\end{abstract}

[a] Prof. Dr. T. Shoji, M. Tanaka, E. Shimomura, Prof. Dr. K. Fujimori Department of Chemistry, Faculty School of Science, Shinshu University

Matsumoto 390-8621, Nagano, Japan

E-mail: tshoji@shinshu-u.ac.jp

[b] Prof. Dr. T. Shoji, A. Maruyama, D. Nagai

Department of Material Science, Graduate School of Science and Technology, Shinshu University

Matsumoto 390-8621, Nagano, Japan

[c] Prof. Dr. S. Ito

Graduate School of Science and Technology, Hirosaki University Hirosaki 036-8561, Aomori, Japan

[d] Prof. Dr. T. Okujima

Department of Chemistry and Biology, Graduate School of Science and Engineering, Ehime University

Matsuyama 790-8577, Ehime, Japan

[e] Prof. Dr. K. Toyota

Department of Chemistry, Graduate School of Science, Tohoku University

Sendai 980-8578, Miyagi, Japan

[f] Prof. Dr. M. Yasunami

Department of Chemical Biology and Applied Chemistry, College of Engineering, Nihon University

Koriyama 963-8642, Fukushima, Japan

Supporting information for this article is given via a link at the end of the document. observed by visible spectroscopy under the electrochemical reduction conditions.

\section{Introduction}

Organic electron donor-acceptor systems, which were featured by intramolecular charge-transfer (ICT) interactions, have attracted considerable interest as promising candidates for the next generation of organic electronic and optoelectronic devices. ${ }^{[1]} \quad$ Especially, aryl-substituted 1,1,4,4-tetracyanobutadienes (TCBDs) and dicyanoquinodimethanes (DCNQs), which are readily prepared by a formal [2 + 2] cycloaddition-retroelectrocyclization (CA-RE) reaction of electron-rich alkynes with tetracyanoethylene $(\mathrm{TCNE})^{[2]}$ and 7,7,8,8-tetracyanoquinodimethane (TCNQ) ${ }^{[3]}$ have been studied due to their potentials as an electronic material such as nonlinear optics, ${ }^{[4]}$ photovoltaics, ${ }^{[5]}$ field effect transistors, ${ }^{[6]}$ and ion sensors. ${ }^{[7]}$

We have also reported the synthesis and properties of azulene-substituted TCBDs (AzTCBDs) and DCNQs (AzDCNQs) connected with various aryl groups, which have been prepared by the $[2+2]$ CA-RE reaction of the corresponding ethynylazulene derivatives with $\mathrm{TCNE}^{[8]}$ and $\mathrm{TCNQ}^{\left[{ }^{[9]}\right.}$ In the study, we have revealed their multistep reduction properties by using cyclic voltammetry (CV) and differential pulse voltammetry (DPV). Moreover, significant color changes have also been clarified by the electrochemical reduction of the AzTCBDs connected with various aryl groups. Recently, we have reported the electronic properties and redox behavior of tris(1-AzTCBD)s and tris(1-AzbisTCBD)s connected to a 1,3,5-tri(1-azulenyl)benzene core. ${ }^{[10]}$ The study suggested the less effective conjugation among the three TCBD units through the 1,3,5-tri(1-azulenyl)benzene core. However, the substituent effect and intramolecular interaction among the AzTCBD units in the molecule have not been thoroughly explored yet. Since the optical and electrochemical properties of the AzTCBDs are affected by both substituted $\pi$-electron system and also number of the TCBD units in the molecule, ${ }^{[2,8]}$ systematic investigation of the effect of the ri-electron systems connected to the AzTCBD units should provide a useful information for the creation of the electronic devices utilizing their redox properties. Therefore, we have investigated the synthesis of new tris-AzTCBDs and 
compared with those of AzTCBDs with their partial structures. These studies should reveal their substitution effect and intramolecular interaction though the 1,3,5-tri(1-azulenyl)benzene core.

Herein we describe a comparative study on optical and electrochemical properties of tris-AzTCBDs and AzTCBDs with their partial structures under the same conditions. Tris-AzTCBDs and AzTCBDs were prepared by the Pd-catalyzed coupling of tris(3-iodo-1-azulenyl)benzene and 3-iodo-1-phenylazulene with arylalkynes, followed by the [2 + 2] CA-RE reaction of the alkyne precursors with TCNE. The optical and electronic properties of the new tris-AzTCBDs and AzTCBDs with their partial structures were investigated by absorption spectroscopy, theoretical calculations, electrochemical analysis, and spectroelectrochemical measurements.

\section{Results and Discussion}

Synthesis of alkyne precursors: To prepare the AzTCBDs 17-20, which become model substructures of the corresponding tris-AzTCBDs 21-24, alkyne precursors 5-7 and 10 were synthesized

from 5-isopropyl-3-methoxycarbonyl-2H-cyclohepta[b]furan-2-one (1) via four- and six-step protocols, respectively. The starting material, methyl 7-isopropyl-3-phenylazulene-1-carboxylate (2) was prepared in $89 \%$ yield by Yasunami-Takase's method by using the reaction of $\mathbf{1}$ with phenylacetaldehyde in the presence of morpholine. ${ }^{[11]}$ The synthesis of $\mathbf{4}$ was established by the removal of the ester function of 2 by heating in $100 \% \mathrm{H}_{3} \mathrm{PO}_{4}$ in $83 \%$ yield, followed by the iodination of the product 3 with $\mathrm{N}$-iodosuccinimide (NIS) at $0{ }^{\circ} \mathrm{C}$ in $99 \%$ yield (Scheme 1). The addition of a small amount of triethylamine in the reaction is essential for the success of the iodination of 3 , since the reaction without the amine base in $\mathrm{CH}_{2} \mathrm{Cl}_{2}$ resulted into the complete decomposition instead of the formation of $4^{[12]}$ The product 4 also showed complete decomposition within a day even at $-30{ }^{\circ} \mathrm{C}$ under an $\mathrm{Ar}$ atmosphere when was stored in solution with a high concentration. However, the product $\mathbf{4}$ was relatively stable at a low concentration that allows the further transformation utilizing the iodide 4 . We have also examined the iodination of $\mathbf{3}$ using NCS and $\mathrm{Nal},{ }^{[8 \mathrm{~d}]}$ but the reaction also led to the decomposition probably due to the same reasons in the reaction with NIS.

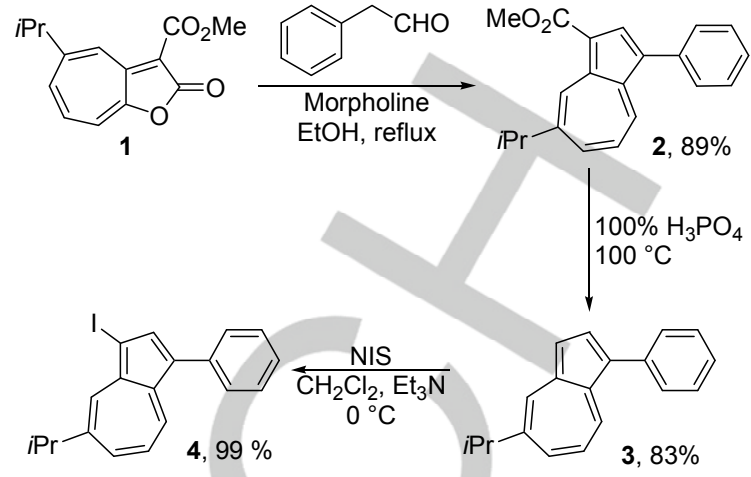

Scheme 1. Synthesis of 1-iodoazulene derivative 4 .

Preparation of the alkyne precursors 5-7 and 10 was accomplished by Pd-catalyzed alkynylation of $\mathbf{4}$ with the corresponding ethynylbenzene derivatives or with 1-ethynylazulene 9 under Sonogashira-Hagihara conditions. The cross-coupling reaction of $\mathbf{4}$ with ethynylbenzene, using $\left[\mathrm{Pd}\left(\mathrm{PPh}_{3}\right)_{4}\right]$ as a catalyst, and subsequent chromatographic purification on silica gel afforded the desired compound $\mathbf{5}$ in $81 \%$ yield. The cross-coupling reaction of 4 with 4-ethynyl- $\mathrm{N}, \mathrm{N}$-dimethylaniline in the presence of the Pd-catalyst afforded 6 in $82 \%$ yield. Compound 7 was obtained by a similar $\mathrm{Pd}$-catalyzed reaction of $\mathbf{4}$ with 4-ethynylnitrobenzene in $93 \%$ yield (Scheme 2). For the synthesis of 10, 1-ethynylazulene $\mathbf{9}$, the coupling partner of the cross-coupling reaction of $\mathbf{4}$, was synthesized by the Sonogashira-Hagihara reaction and deprotection sequence. Thus, the cross-coupling reaction of 4 with trimethylsilylacetylene and $\left[\mathrm{Pd}\left(\mathrm{PPh}_{3}\right)_{4}\right]$ as a catalyst at $50{ }^{\circ} \mathrm{C}$ gave 8 in $96 \%$ yield. Alkyne 9 was obtained by the treatment of 8 with $\mathrm{K}_{2} \mathrm{CO}_{3}$ in $\mathrm{MeOH}$, but we found out that the product 9 was very unstable and readily decomposed in both purification and evaporation processes. Thus, the cross-coupling reaction of 4 with the alkyne $\mathbf{9}$ was performed without purification of $\mathbf{9}$ to obtain the compound 10 (65\% yield). To conclude, the reaction of the alkynes with 4 gave the corresponding products 5-7 in good yields, whereas the reaction of 1-ethynylazulene 9 with 4 produced the cross-coupling product in a relatively low yield, due to the instability of $\mathbf{9}$. 

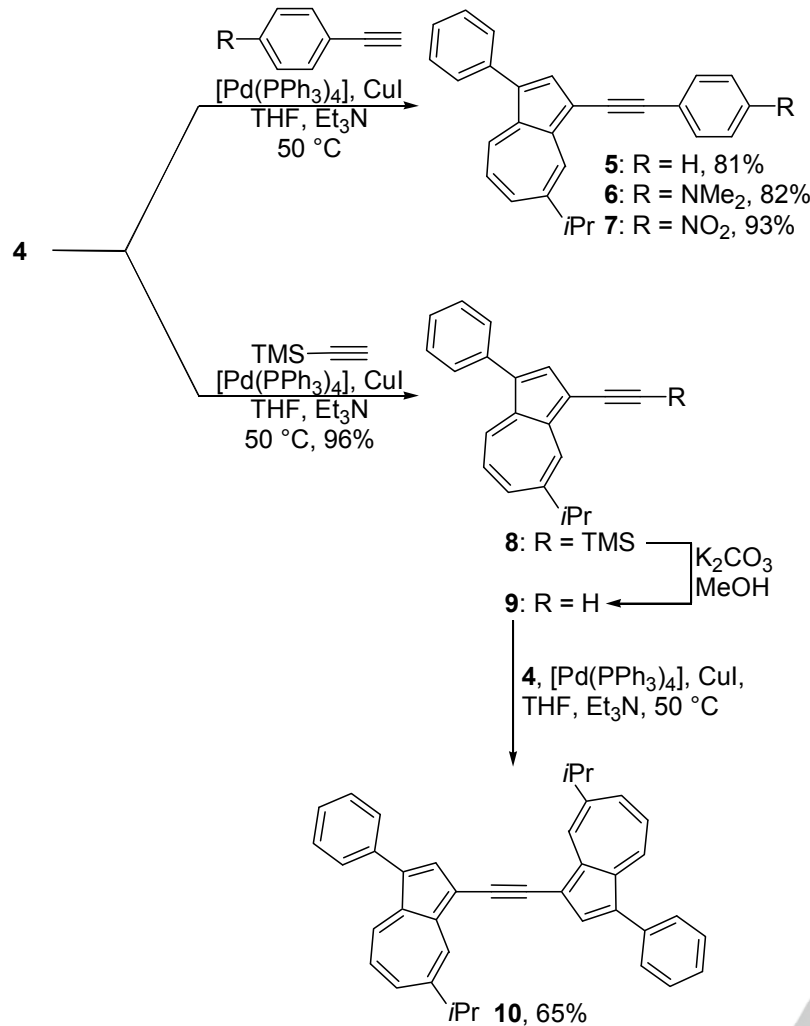

Scheme 2. Synthesis of the alkyne precursors 5-7 and 10

Preparation of 1,3,5-tris(3-arylethynyl-1-azulenyl)benzene derivatives 13-16 was accomplished by the SonogashiraHagihara reaction of tris(3-iodo-1-azulenyl)benzene derivative 12 prepared from 11 by the three-steps procedure as reported by us recently ${ }^{[10]}$ with the alkyne precursors 5-7 and 10 (Scheme 3). Compound 13 was obtained in $81 \%$ yield by the cross-coupling reaction of 12 with ethynylbenzene in the presence of $\left[\mathrm{Pd}\left(\mathrm{PPh}_{3}\right)_{4}\right]$ as a catalyst in $\mathrm{THF} /$ triethylamine at $50^{\circ} \mathrm{C}$. As similar to the reaction described above, Sonogashira-Hagihara reaction of 12 with 4-ethynyl- $N, N$-dimethylaniline and 4-ethynylnitrobenzene gave the corresponding cross-coupled products 14 and 15 in $69 \%$ and $93 \%$ yields, respectively. The reaction of 12 with alkyne 9 afforded 15 in $69 \%$ yield, by the similar procedure for the preparation of $\mathbf{1 0}$. The alkynes 5-7 and 10, and 1,3,5-tris(3-arylethynyl-1-azulenyl)benzene derivatives 13-16 possess fair solubility in common organic halogen solvents, such as chloroform and dichloromethane. Moreover, they are stable and show no decomposition even after several weeks at room temperature. Thus, these alkynes could be utilized in further transformations for the synthesis of new AzTCBD derivatives with 3-phenyl-1-azulenyl function because of their stability and solubility.

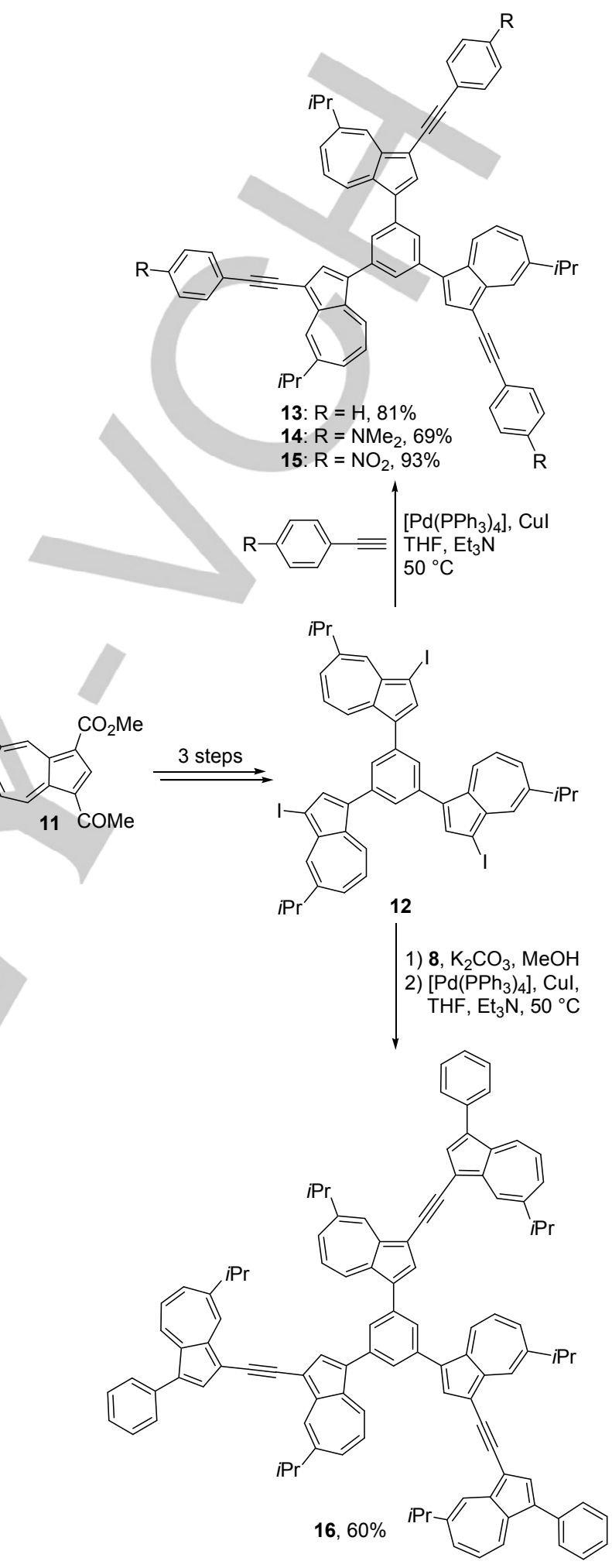

Scheme 3. Synthesis of 1,3,5-tris(3-arylethynyl-1-azulenyl)benzene derivatives 13-16. 
Reaction of alkynes with TCNE: For the synthesis of new AzTCBDs 17-20 and tris-AzTCBDs 21-24, formal [2 + 2] CA-RE reaction of the alkyne precursors 5-7 and 10, and 13-16 with TCNE was examined according to the procedure described in the literature (Scheme 4). ${ }^{[2,8]}$ Thus, the reaction of 5 with TCNE in AcOEt at room temperature yielded 17 in $79 \%$ yield. The reaction of 6 with TCNE in AcOEt afforded 18 in 66\% yield. Alkyne derivative 7, which possesses electron-withdrawing nitro groups at the para-position on the phenylethynyl moiety, also reacted readily with TCNE to afford the corresponding TCBD derivative 19 in $93 \%$ yield. The reaction of 7 proceeded at a relatively low reaction temperature for a short reaction period, although the strong electron-withdrawing group on the phenylethynyl moiety generally shows a tendency to decrease the reactivity toward the CA-RE reaction. The high reactivity of 7 can be ascribed to the higher electron-donating property of 1-azulenyl group. $\mathrm{Di}(1$-azulenyl)acetylene derivative $\mathbf{9}$ also reacted with TCNE in the mixed solvent of $\mathrm{AcOE} t / \mathrm{CH}_{2} \mathrm{Cl}_{2}$ to afford the corresponding product 20 in $62 \%$ yield. ${ }^{[13]}$

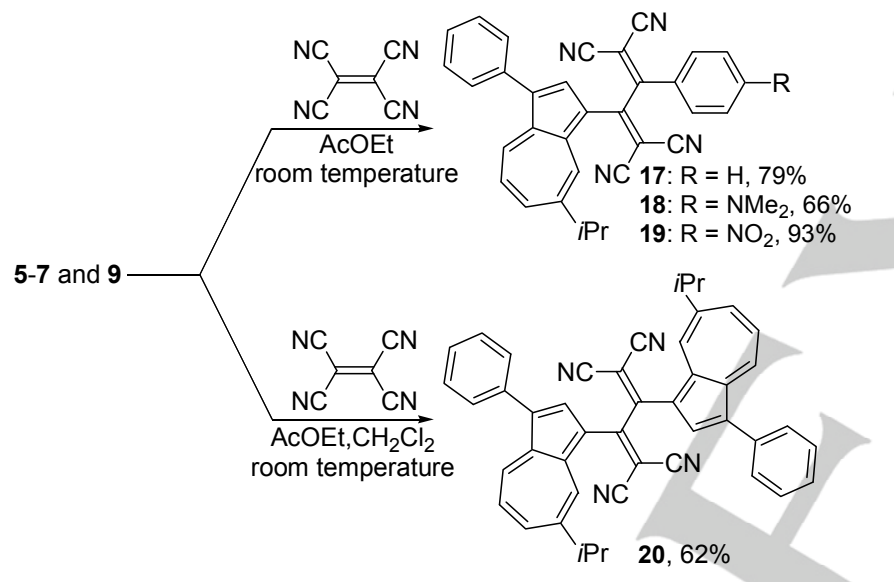

Scheme 4. The formal [2 + 2] CA-RE reaction of alkyne derivatives 5-7 and 10 with TCNE.

Tris-alkyne precursors $\mathbf{1 3 - 1 6}$ also reacted with TCNE, as similar to the reaction of alkynes 5-7 and 10, to afford the corresponding tris-AzTCBDs 21-24 (Scheme 5). Tris-AzTCBD 20 with unsubstituted-phenyl groups was obtained in quantitative yield by the reaction of 13 with TCNE in $\mathrm{CH}_{2} \mathrm{Cl}_{2}$ at the refluxing temperature. The reaction of tris-alkyne precursors 14 and 15 with TCNE yielded the corresponding tris-AzTCBDs 22 and 23 in $88 \%$ and $97 \%$ yields, respectively. The [2 + 2] CA-RE reaction of tris-alkyne precursor 16 with TCNE also afforded the corresponding tris-AzTCBD 24 in 93\% yield under the similar reaction conditions. The new AzTCBDs 17-20 and tris-AzTCBDs 21-24 are stable, deep red-colored crystals that can be stored in the crystalline state at ambient temperature under aerobic conditions.

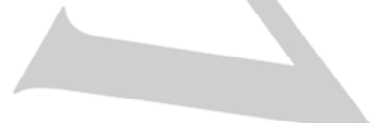

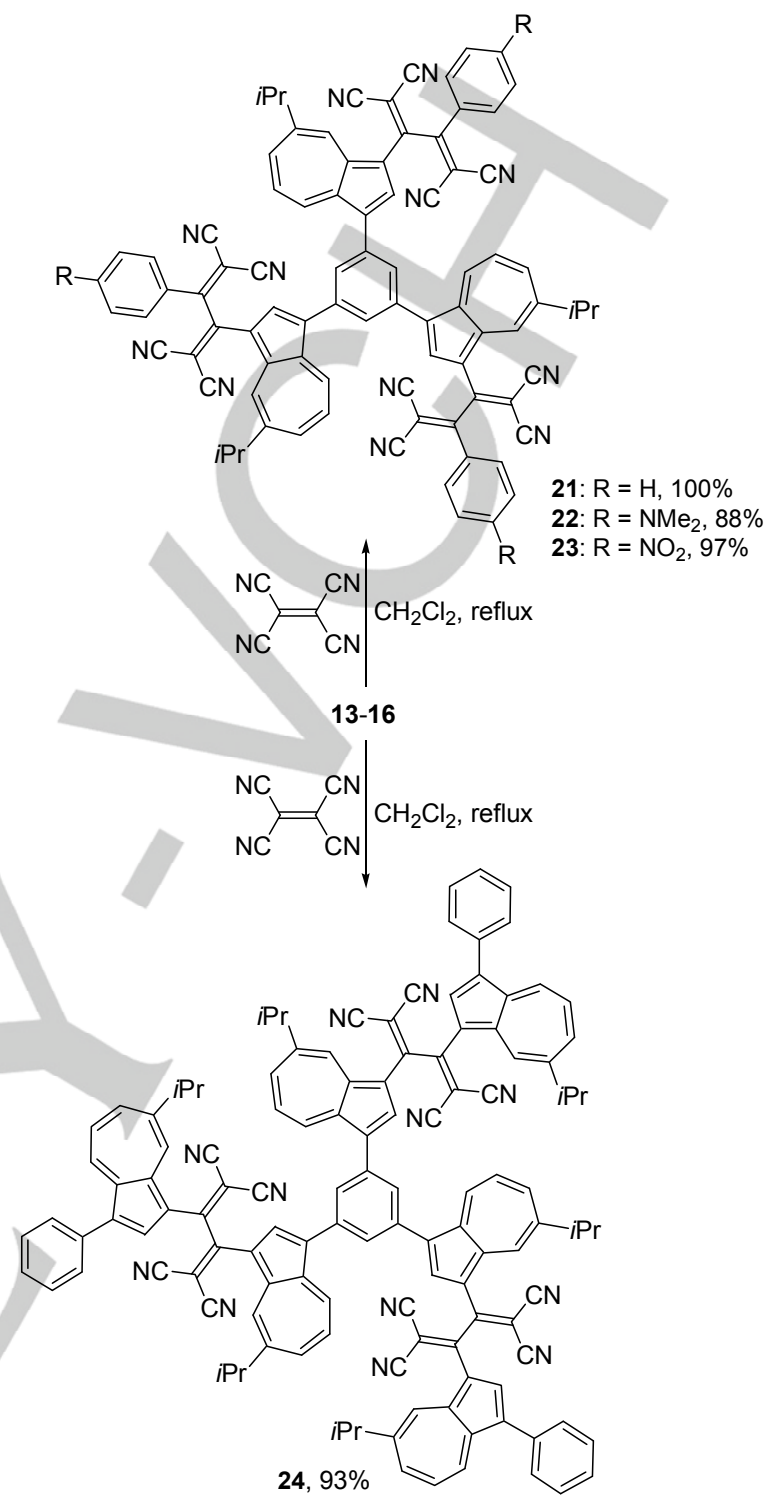

Scheme 5. The formal [2 + 2] CA-RE reaction of tris-alkyne precursors 13-16 with TCNE.

Spectroscopic properties: The new AzTCBDs 17-20 and tris-AzTCBDs 21-24 were fully characterized based on their spectral data, as summarized in the Experimental Section. High-resolution mass spectra of AzTCBDs 17-20 and tris-AzTCBDs 21-24 ionized by FAB or MALDI-TOF conditions showed the correct molecular ion peaks. The characteristic stretching vibration band of the $\mathrm{C} \equiv \mathrm{N}$ moieties of the AzTCBDs 17-20 and tris-AzTCBDs 21-24 was observed at $\mathrm{v}_{\max }=2210$ $2218 \mathrm{~cm}^{-1}$ in their IR spectra. The NMR spectroscopic assignment of the new compounds was confirmed by COSY, HMQC, and HMBC experiments. These results are consistent with the given structure of these products. In the ${ }^{1} \mathrm{H}$ NMR spectra, downfield shifts for seven-membered ring protons $(\mathrm{H}-6, \mathrm{H}-7$, and $\mathrm{H}-8$ ) of the azulene moiety of the tris-TCBDs 21-24 were 
observed in $\mathrm{CDCl}_{3}$ compared with those of the tris-alkyne precursors 13-16, which are attributable to the resonance effect with the strong electron-withdrawing TCBD group as represented in Scheme 6. Although chemical shifts for the azulene moiety of the tris-alkyne precursors 13-16 and those of tris-TCBDs 21-24 were also affected by the substituent on the arylethynyl moieties on the TCBD units, ring-protons of the central benzene core were almost the same values. Therefore, these results suggested the less effective conjugation among the three ethynylarene moieties and the three TCBD units through the central benzene core.

UV/Vis spectra of AzTCBDs 17-20 and tris-AzTCBDs 21-24 are shown in Figures 1 and 2, respectively. The absorption maxima $\left(\lambda_{\max }\right)$ and their coefficients (log $\varepsilon$ ) of the new compounds are summarized in the Experimental Section. The UV/Vis spectra of the alkyne precursors 5-7 and 10, and 1,3,5-tris(3-arylethynyl-1-azulenyl)benzene derivatives 13-16 showed characteristic weak absorptions at around 610-760 nm, arising from the azulene system (see the Supporting Information) Slight bathochromic shift for the longest wavelength absorption bands of alkyne precursors 5-7 and $\mathbf{1 0}$ compared with that of the parent derivative $3\left(\lambda_{\max }=608 \mathrm{~nm}\right.$, Figure S-41) might be attributed to the extension of the m-electron system by the arylethynyl moiety. Alkynes $\mathbf{7}$ and $\mathbf{1 5}$ with $p$-nitrophenyl substituents also exhibited relatively strong absorption bands at around $460 \mathrm{~nm}$, which may be explained by intramolecular charge transfer (ICT) between the azulene and nitrobenzene moieties through the $\mathrm{C} \equiv \mathrm{C}$ triple bond.

UV/Vis spectra of AzTCBDs 17-20 were depended on the nature of the substituents on the aryl groups on the TCBD moieties. AzTCBDs 17 and 19 exhibited a broad CT absorption centered at $\lambda_{\max }=509 \mathrm{~nm}$ and $467 \mathrm{~nm}$, respectively (Figure 1). On the other hand, the UV/Vis spectrum of the AzTCBD 18 with $\mathrm{N}, \mathrm{N}$-dimethylamino function exhibited an strong absorption band at $\lambda_{\max }=477 \mathrm{~nm}$, which was leaving beyond to $750 \mathrm{~nm}$. The absorption band of $\mathbf{1 8}$ should be concluded to the ICT from both azulene and $\mathrm{N}, \mathrm{N}$-dimethylaniline moieties to the TCBD unit as illustrated in Scheme 6 , since the wavelength of the absorption maximum of 18 resembled with that of TCBD $25\left(\lambda_{\max }=481\right.$ $\mathrm{nm})^{[2 \mathrm{a}]}$ and $26\left(\lambda_{\max }=474 \mathrm{~nm}\right)^{[9 \mathrm{~b}]}$ with the $N, N$-dimethylaniline moiety (Figure 3 ). The longest wavelength band of 19 spread up to $800 \mathrm{~nm}$, and the absorption band displayed a bathochromic shift compared with those of $\mathbf{1 7}$ and 18. Thus, the nitrobenzene substituent on the TCBD moiety might be concluded to decrease the HOMO-LUMO gap of 19, with respect to the results on the UV/Vis spectra. UV/Vis spectra of symmetric AzTCBD 20 revealed a broad absorption band at $\lambda_{\max }=541 \mathrm{~nm}$ in $\mathrm{CH}_{2} \mathrm{Cl}_{2}$, and absorption coefficient was about two-fold larger than that of 17, due to the overlap of ICT between two-azulenyl groups to the central TCBD moiety (Scheme 6). The absorption maxima of $\mathbf{2 0}$ showed a bathochromic shit compared to that of di(1-azulenyl)TCBD $27\left(\lambda_{\max }=508 \mathrm{~nm}\right){ }^{[8 \mathrm{a}]}$ These results suggest that the $\pi$-conjugation is effectively extended by the phenyl substituent at the 3-position on the azulene ring.

UV/Vis spectra of tris-AzTCBDs 21-24 connected by the central benzene core revealed a broad absorption band at visible region in $\mathrm{CH}_{2} \mathrm{Cl}_{2}$, which reached to the near-infrared region (Figure 2). The intensities for the absorption band of
tris-AzTCBDs 21-24 were almost three-times larger than those of the corresponding AzTCBDs 17-20, although the absorption maxima were observed at almost the same wavelengths. The similarity of the absorption maxima of 21-24 suggests the less effective conjugation of the three TCBD units in the 1,3,5-arrangement through the centred benzene ring.

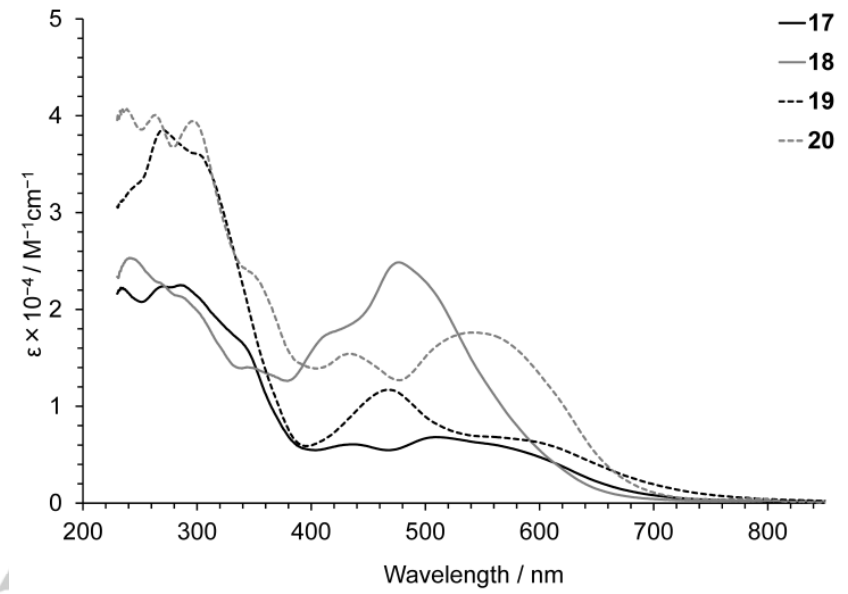

Figure 1. UV/Vis spectra of AzTCBDs 17 (black line), 18 (gray line), 19 (black-dot line), and 20 (gray-dot line) in $\mathrm{CH}_{2} \mathrm{Cl}_{2}$.

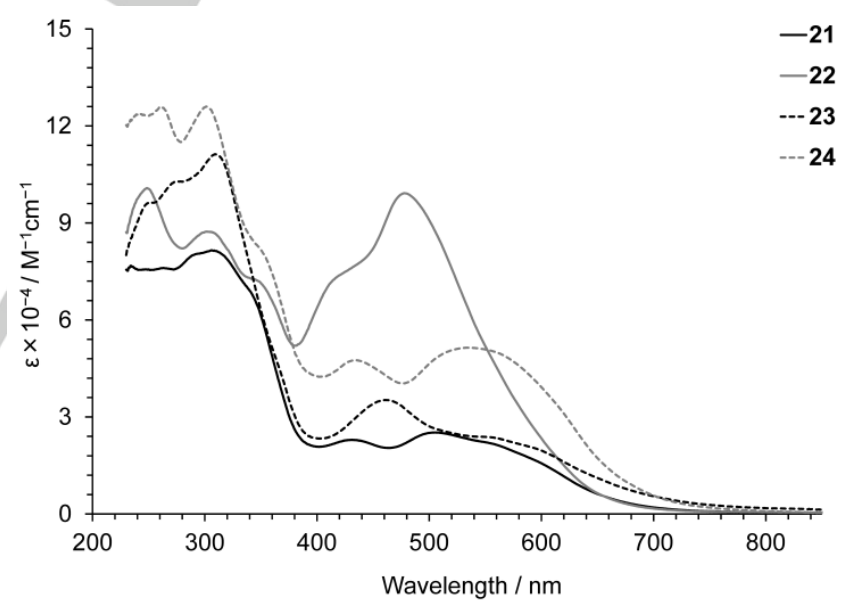

Figure 2. UV/Vis spectra of AzTCBDs 21 (black line), 22 (gray line), 23 (black-dot line), and 24 (gray-dot line) in $\mathrm{CH}_{2} \mathrm{Cl}_{2}$. 
<smiles>CN(C)c1ccc(C(C=C(C#N)C#N)=C(C#N)C#N)cc1</smiles><smiles></smiles>

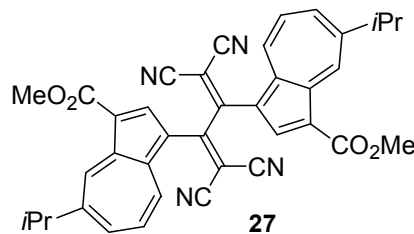

Figure 3. Structures of $\mathrm{N}, \mathrm{N}$-dimethylanilinoTCBDs 25 and 26, and di(1-azulenyl)TCBD 27
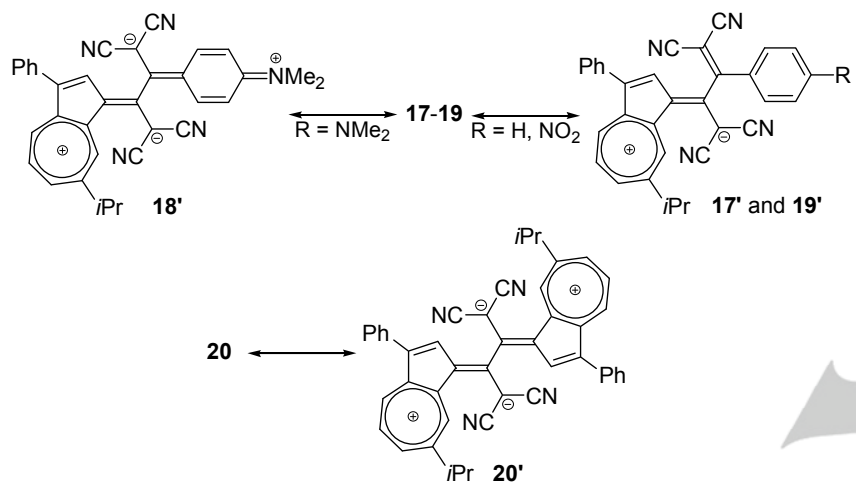

Scheme 6. Presumed resonance structure of AzTCBDs 17-20.

To elucidate the nature of the absorption bands, time-dependent density functional theory (TD-DFT) calculations at the B3LYP/6-31G** level ${ }^{[14]}$ were carried out on 1-phenylazulene (3), alkynes 5-7 and 10, and AzTCBDs 17-19 and 20", in which the two phenyl groups at the 3-position on azulenyl groups were replaced by hydrogen for the simplicity. The frontier Kohn-Sham orbitals of these compounds are shown in the Supporting Information (Figures S-76 to S-83). Judging from a comparison between the experimental and the theoretical UV/Vis spectra, the longest wavelength absorptions of alkynes 5-7 could be assigned to overlap of $\pi-\Pi^{*}$ transition of the substituted azulene ring itself, and arylethynyl moieties to azulene ring. The strong absorption band at $\lambda_{\max }=454 \mathrm{~nm}$ of 7 is revealed as the transition from the HOMO located on the 3-phenylazulene moiety to LUMO and LUMO+1, spread in both azulene and nitrobenzene moieties (Figure S-94). Therefore, this band could be assigned as ICT arising from the 3-phenylazulene to nitrobenzene moieties. The HOMOs and LUMOs of 10 displayed symmetrical orbitals with respect to its symmetrical structure (Figure S-95). The ICT of 10 confirmed that the longest wavelength absorption arise from HOMO to LUMO and LUMO+1, which mainly located on both azulene rings The strong absorption at around $420-460 \mathrm{~nm}$ of 10 was also attributed to the overlapping of the ICT absorptions between the two-azulenyl groups (Table 1 and Figure S-95).
Most AzTCBDs 17-20" have a cisoid structure in the TCBD unit at the B3LYP/6-31G ${ }^{* *}$ optimized geometry. The HOMOs and LUMOs of the AzTCBDs 17-20" are mainly distributed on the azulene ring and TCBD moieties, respectively (Figures S-96 to Figure S-99). Thus, broad absorption bands in the visible region of AzTCBDs 17-20" could be concluded to the ICT between the azulene ring and TCBD moieties. In detail the theoretical calculations clarified that the broad ICT of $\mathbf{1 7}$ originated from the $\mathrm{HOMO}$ and HOMO-1 located on 3-phenylazulene moiety to the LUMO and LUMO+2 that was mainly located on the TCBD moiety and LUMO+1 located on the azulene ring, although the contribution of HOMO-LUMO+1 transition was relatively low (Figure S-96). The strong absorption band of 18 at $\lambda_{\max }=477$ $\mathrm{nm}$ could be ascribed to some ICT characters of the transitions from $N, N$-dimethylaniline moiety $(\mathrm{HOMO}-1)$ to both 3-phenylazulene and the TCBD moieties (LUMO, LUMO+1, and LUMO+2) as predicted by a resonance structure of 18 (Figure $\mathrm{S}-97)$. The broad absorption band of 19 in the visible region is considered as the $\pi-\pi^{*}$ transition between the HOMO, which located on the 3-phenylazulene moiety, and LUMO, LUMO+1, and LUMO+2, which spread in both nitrobenzene and TCBD moieties (Figure S-98). Thus, the nitrobenzene moiety of 19 contributes to the lower HOMO-LUMO gap $(\Delta E=2.21 \mathrm{eV})$ toward $17(\Delta E=2.47 \mathrm{eV})$ and $18(\Delta E=2.64 \mathrm{eV})$, and the effective extension of the $\pi$-electron system between 3-phenylazulene and nitrobenzene-substituted TCBD moieties. The ICT of 20" was confirmed by the longest absorption band arose from the HOMOs located at the two azulene rings to the LUMOs located mainly on the TCBD moiety (Figure S-99). Thus, the strong absorption of $\mathbf{2 0}$ in the visible region is attributed to the overlapping of the CT absorption from the two azulene moieties in the both terminals to the central TCBD unit. As the conclusion, influences of aryl substituent on the TCBD unit in the absorption maximum of the AzTCBDs 17-20 were reasonably explained by the theoretical calculations.

Table 1. Electronic transitions for 1-phenylazulene (3), alkynes 5-7 and 10, and AzTCBDs 17-20", derived from the computed values based on B3LYP/6-31G** method and experimental values

\begin{tabular}{|c|c|c|c|}
\hline Sample & $\begin{array}{l}\text { Experimental } \\
\lambda_{\max }(\log \varepsilon)\end{array}$ & $\begin{array}{l}\text { Computed value } \\
\lambda_{\max } \text { (strength) }\end{array}$ & $\begin{array}{l}\text { Composition of band } \\
\text { (amplitude) }\end{array}$ \\
\hline \multirow[t]{2}{*}{5} & $400(4.04)$ & $394(0.2692)$ & $\begin{array}{l}H-1 \rightarrow L(0.5286) \\
H \rightarrow L+1(0.8271)\end{array}$ \\
\hline & $633(2.59)$ & $611(0.0102)$ & $\mathrm{H} \rightarrow \mathrm{L}(0.9817)$ \\
\hline \multirow[t]{3}{*}{6} & $402(4.16)$ & $396(0.3566)$ & $\begin{array}{l}H-1 \rightarrow L(0.6206) \\
H \rightarrow L+1(0.6892)\end{array}$ \\
\hline & $427 \mathrm{sh}(4.08)$ & $428(0.1436)$ & $\mathrm{H}-1 \rightarrow \mathrm{L}(0.7384)$ \\
\hline & $\begin{array}{l}659 \mathrm{sh}(2.75) \\
715(2.82)\end{array}$ & $652(0.0111)$ & $\mathrm{H} \rightarrow \mathrm{L}(0.9756)$ \\
\hline \multirow[t]{2}{*}{7} & $454(4.33)$ & $467(0.7542)$ & $\begin{array}{l}\mathrm{H} \rightarrow \mathrm{L}(0.9402) \\
\mathrm{H} \rightarrow \mathrm{L}+1(0.2644)\end{array}$ \\
\hline & $613 \mathrm{sh}(2.84)$ & $592(0.0106)$ & $\mathrm{H} \rightarrow \mathrm{L}+1(0.9478)$ \\
\hline
\end{tabular}




\begin{tabular}{|c|c|c|c|c|c|c|c|c|c|}
\hline \multirow[t]{5}{*}{10} & $426 \mathrm{sh}(4.25)$ & $420(0.4064)$ & $\mathrm{H}-1 \rightarrow \mathrm{L}+1(0.7929)$ & \multirow{2}{*}{\multicolumn{6}{|c|}{$\begin{array}{l}\text { of AzTCBDs 17-20 and tris-AzTCBDs 21-24 are summarized in } \\
\text { Table } 2 . \\
\text { Table 2. Redox potentials }{ }^{[a, b]} \text { of AzTCBDs 17-20 and tris-AzTCBDs 21-24. }\end{array}$}} \\
\hline & $435 \mathrm{sh}(4.25)$ & $439(0.4064)$ & $\mathrm{H}-1 \rightarrow \mathrm{L}(0.8473)$ & & & & & & \\
\hline & $461(4.23)$ & $454(0.4611)$ & $\begin{array}{l}\mathrm{H}-1 \rightarrow \mathrm{L}+1(0.5511) \\
\mathrm{H} \rightarrow \mathrm{L}+2(0.7863)\end{array}$ & Sample & Method & $E_{1}{ }^{\mathrm{ox}}[\mathrm{V}]$ & $E_{1}^{\text {red }}[\mathrm{V}]$ & $E_{2}^{\text {red }}[\mathrm{V}]$ & $E_{3}^{\text {red }}[\mathrm{V}]$ \\
\hline & $655(2.96)$ & $681(0.0026)$ & $H \rightarrow L+1(0.9356)$ & 17 & $\mathrm{CV}$ & & -0.67 & -1.08 & \\
\hline & $733(2.77)$ & $682(0.0193)$ & $\begin{array}{l}\mathrm{H} \rightarrow \mathrm{L}(0.9336) \\
\mathrm{H} \rightarrow \mathrm{L}+1(0.2814)\end{array}$ & 18 & (DPV) & $(+0.97)$ & $(-0.65)$ & $(-1.06)$ & $(-1.86)$ \\
\hline \multirow[t]{4}{*}{17} & $436(3.77)$ & $433(0.0697)$ & $\begin{array}{l}H-1 \rightarrow L(0.6817) \\
H \rightarrow L+2(0.6656)\end{array}$ & & (DPV) & $(+0.95)$ & $(-0.84)$ & $(-1.16)$ & $(-1.82)$ \\
\hline & $509(3.82)$ & $552(0.0035)$ & $\mathrm{H} \rightarrow \mathrm{L}+1(0.9774)$ & 19 & $\mathrm{CV}$ & & -0.52 & -0.92 & \\
\hline & $564 \operatorname{sh}(3.76)$ & & & & & & $(-0.50)$ & $(-0.90)$ & $(-1.63)^{[\mathrm{d}]}$ \\
\hline & $614 \operatorname{sh}(3.60)$ & $608(0.0584)$ & $\begin{array}{l}\mathrm{H} \rightarrow \mathrm{L}(0.9452) \\
\mathrm{H} \rightarrow \mathrm{L}+2(0.2904)\end{array}$ & 20 & $\mathrm{CV}$ & & -0.75 & -1.13 & \\
\hline \multirow[t]{7}{*}{18} & $411 \mathrm{sh}(4.23)$ & $417(0.1395)$ & $\mathrm{H}-2 \rightarrow \mathrm{L}+1(0.2647)$ & & (DPV) & $(+0.96)$ & $(-0.73)$ & $(-1.11)$ & $(-1.86)$ \\
\hline & & & $\begin{array}{l}H \rightarrow L(0.2145) \\
H \rightarrow L+2(0.7541)\end{array}$ & 21 & $\mathrm{CV}$ & & -0.68 & -1.07 & \\
\hline & 477 (4.39) & $450(0.0011)$ & $\mathrm{H}-1 \rightarrow \mathrm{L}+1 \quad(0.9909)$ & & (DPV) & $(+1.02)$ & $(-0.66)$ & $(-1.05)$ & \\
\hline & & $486(0.0644)$ & $\mathrm{H}-1 \rightarrow \mathrm{L}(0.9113)$ & 22 & CV & & -0.86 & -1.17 & \\
\hline & & & $\mathrm{H}-1 \rightarrow \mathrm{L}+2(0.3139)$ & & (DPV) & $(+0.99)$ & $(-0.84)$ & $(-1.15)$ & \\
\hline & $620 \mathrm{sh}(3.53)$ & $543(0.0701)$ & $\mathrm{H} \rightarrow \mathrm{L}(0.8521)$ & 23 & $\mathrm{CV}$ & & -0.52 & -0.91 & \\
\hline & & $557(0.0205)$ & $\mathrm{H} \rightarrow \mathrm{L}+1(0.9046)$ & & (DPV) & $(+1.00)$ & $(-0.50)$ & $(-0.89)$ & $(-1.58)^{[\mathrm{e}]}$ \\
\hline \multirow[t]{2}{*}{19} & $432 \mathrm{sh}(3.93)$ & $441(0.0777)$ & $\begin{array}{l}\mathrm{H}-1 \rightarrow \mathrm{L}(0.8140) \\
\mathrm{H} \rightarrow \mathrm{L}+1(0.4419)\end{array}$ & 24 & $\mathrm{CV}$ & & -0.75 & -1.11 & \\
\hline & & & $\mathrm{H} \rightarrow \mathrm{L}+3(0.3044)$ & & (DPV) & $(+0.96)$ & $(-0.73)$ & $(-1.09)$ & $(-1.78)$ \\
\hline
\end{tabular}

\begin{tabular}{lll}
$467(4.06)$ & $479(0.1115)$ & $H \rightarrow L+1(0.8185)$ \\
$595 \operatorname{sh}(3.79)$ & $553(0.0042)$ & $H \rightarrow L+2(0.9782)$ \\
$698 \operatorname{sh}(3.27)$ & $717(0.0253)$ & $H \rightarrow L(0.9763)$ \\
\hline $435(4.19)$ & $422(0.0159)$ & $H-1 \rightarrow L+1(0.4899)$ \\
& $452(0.0715)$ & $H-1 \rightarrow L+2(0.6949)$ \\
& & $H \rightarrow L+2(0.6635)$ \\
& $462(0.0042)$ & $H-1 \rightarrow L(0.7495)$ \\
& & $H \rightarrow L+2(0.2555)$ \\
& $482(0.0060)$ & $H \rightarrow L+1(0.6163)$ \\
& & $H \rightarrow L+3(0.6453)$ \\
& $511(0.0030)$ & $H-1 \rightarrow L+1(0.2470)$ \\
& & $H \rightarrow L+3(0.6549)$ \\
& & $H-1 \rightarrow L(0.5838)$ \\
& & $H \rightarrow L(0.7504)$ \\
& $519(0.0028)$ &
\end{tabular}

[a] $\mathrm{H}=\mathrm{HOMO}, \mathrm{L}=$ LUMO.

Electrochemical properties: To clarify the electrochemical properties, the redox behavior of alkynes 5-7 and 10, tris-alkynes 13-16, AzTCBDs 17-20, and tris-AzTCBDs 21-24 was examined by CV and DPV. ${ }^{[15]}$ Cyclic and differential pulse voltammograms of these compounds are summarized in the Supporting Information. The redox potentials (in $\mathrm{V}$ vs. $\mathrm{Ag} / \mathrm{AgNO}_{3}$ )

[a] $\mathrm{V}$ versus $\mathrm{Ag} / \mathrm{AgNO}_{3}, 1 \mathrm{mM}$ in benzonitrile containing $\mathrm{Et}_{4} \mathrm{NClO}_{4}(0.1 \mathrm{M}), \mathrm{Pt}$ electrode (internal diameter: $1.6 \mathrm{~mm}$ ), scan rate $=100 \mathrm{mVs}^{-1}$ and internal reference $\left(\mathrm{Fc} / \mathrm{Fc}^{+}=+0.15 \mathrm{~V}\right)$. [b] Half-wave potentials $E^{\text {ox }}$ and $E^{\text {red }}=\left(E_{\mathrm{pc}}+\right.$ $\left.E_{\mathrm{pa}}\right) / 2$ on $\mathrm{CV}, E_{\mathrm{pc}}$ and $E_{\mathrm{pa}}$ correspond to the cathodic and anodic peak potentials, respectively. [c] $E_{2}{ }^{\text {ox }}$ was observed at $+1.15 \mathrm{~V}$. [d] $E_{4}{ }^{\text {red }}$ was observed at $-2.01 \mathrm{~V}$ on DPV. [e] $E_{4}^{\text {red }}$ was observed at $-2.05 \mathrm{~V}$ on DPV.

Alkynes 5-7 and 10 and tris-alkynes 13-16 exhibited quasi-reversible or irreversible reduction waves on CV (Figures S-100 to S-115). These results suggest the generation of unstable anionic species of these derivatives under the electrochemical reduction conditions. On the contrary, all AzTCBD chromophores showed reversible two-stage reduction waves on CV. As shown in Table 1, the reduction potentials were significantly affected by the terminal groups in AzTCBD 17-20 and tris-AzTCBDs 21-24. Reversible two-stage reduction wave in AzTCBD chromophores 17-20 should be attributed to the stepwise reduction to a radical anionic and a dianionic species. The first reduction potential of AzTCBD 17-19 depended on the nature of the para-substituent on the terminal benzene ring. The first reduction potential of $19(-0.52 \mathrm{~V})$ was less negative than that of $17(-0.67 \mathrm{~V})$ and $18(-0.86 \mathrm{~V})$. These results reflect that the electron-withdrawing nitro substituent on the aromatic ring directly affects to decrease the LUMO level of the molecule, as expected by the theoretical calculations. In contrast, more negative first reduction potential of $\mathbf{1 8}$ compared with that of $\mathbf{1 7}$ is due to the increment of LUMO level by the electron-donating 
nature of $\mathrm{N}, \mathrm{N}$-dimethylamino group. AzTCBD 20 with two-azulenyl substituents also exhibited the two-stage reduction waves at $-0.75 \mathrm{~V}$ and $-1.13 \mathrm{~V}$ as half-wave potentials. The less negative first reduction potential of $\mathbf{2 0}$ compared to that of $\mathbf{1 8}$ should be reflected by the weaker electron-donating ability of the 1-azulenyl group than that of $N, N$-dimethylamino substituent as predicted by Diederich et al. ${ }^{[16]}$

Electrochemical reduction of tris-AzTCBDs 21-24 displayed only reversible two-waves on $\mathrm{CV}$ owing to the reduction of the TCBD units, although multiple TCBD units existed in the molecules. These results indicate that the three TCBD units in tris-AzTCBDs 21-24 are reduced simultaneously in each step under the electrochemical reduction conditions. Moreover, reduction potentials of tris-AzTCBDs 21-24 are consistent with those of the corresponding AzTCBDs 17-20 (Table 1). Thus, the redox interaction among the three TCBD moieties through the central benzene core is almost negligible from the view point of electrochemical reduction.

In summary, spectral and electrochemical features of AzTCBDs were directly affected by the nature of the substituted aromatic group on the TCBD unit. However, there is little electronic interaction among the three TCBD moieties of tris-AzTCBDs 21-24 on benzene ring, with respect to their UV/Vis and voltammetry experiments. Thus, ICT and redox reaction of tris-AzTCBDs 21-24 are caused independently by each AzTCBD units, and meta connection of three TCBD units through the 1,3,5-benzentriyl spacer should prevent their electronic communication.

The visible spectra of the new compounds were also monitored to clarify the color changes during the electrochemical reactions. The visible spectra were summarized in the Supporting Information. Constant-voltage oxidation and reduction was applied to the solutions with a platinum mesh as the working electrode and a wire counter electrode in an electrolytic cell of $1 \mathrm{~mm}$ thickness. Visible spectra were measured in degassed benzonitrile containing $\mathrm{Et}_{4} \mathrm{NClO}_{4}(0.1 \mathrm{M})$ as a supporting electrolyte at room temperature under the electrochemical reaction conditions.

Alkynes 5, 6 and 10 and tris-alkynes 13,14 and 16 showed a color change with considerable reversibility under the electrochemical redox conditions, although the CV waves were almost irreversible. For example, electrochemical reduction of $\mathbf{1 0}$ gradually developed an absorption band at around $535 \mathrm{~nm}$ along with a decrement of the absorption band at around $450 \mathrm{~nm}$. The color of the solution gradually changed from green to purple during the electrochemical reduction. Reverse oxidation of the purple-colored solution regenerated the parent spectrum of 10 (Figure S-54). However, the color change of alkyne 7 and tris-alkyne 15 with nitrobenzene moieties did not recover the original colors, although the good reversibility was overserved on CV (Figures S-51 and S-63).

Visible spectra of AzTCBD 17-20 and tris-AzTCBDs 21-24 were measured under the electrochemical reduction conditions. The electrochromic behavior was significantly affected by the aromatic substituents on the AzTCBD 17-20 and tris-AzTCBDs 21-24. When the spectral changes of 17 were monitored under the electrochemical reduction conditions at $-0.90 \mathrm{~V}$, the absorption in the visible region gradually increased with the development of new absorption bands at $\lambda_{\max }=540 \mathrm{~nm}$ and $\lambda_{\max }$ $=700 \mathrm{~nm}$, which reached to the near infrared region. The color change should be attributable to the formation of an anionic species formed by the electrochemical reduction of 17 . Reverse oxidation of the reduced species regenerated the original spectrum of 17 (Figure S-69). The reddish-purple color of the solution of AzTCBD 18 changed to yellow during the electrochemical reduction at $-1.05 \mathrm{~V}$ together with the development of an absorption band at around $700 \mathrm{~nm}$ along with an isosbestic point at $615 \mathrm{~nm}$. Reverse oxidation of the yellow-colored solution developed the absorption band at around $490 \mathrm{~nm}$ and regenerated the parent color of 18 (Figure S-72). The reversible two-stage color changes were observed in electrochemical redox reactions. Visible spectra of 19 were measured under electrochemical reduction conditions at $-0.75 \mathrm{~V}$, the absorption band at around $800 \mathrm{~nm}$ gradually increased, and further reduction at $-1.20 \mathrm{~V}$ of the solution turned to deep-brown together with the development of absorption at infrared region, along with two isosbestic points at $520 \mathrm{~nm}$ and $660 \mathrm{~nm}$ (Figure $S-75)$. Reverse oxidation of the reduced species decreased the new absorption bands, along with recovery of the original spectrum of 19 . The two-stage color changes of 19 should be attributable to the stabilization of anionic species generated by electrochemical reduction by electron-withdrawing $p$-nitrophenyl group. When visible spectra of $\mathbf{2 0}$ were measured under electrochemical reduction conditions, absorption of $\mathbf{2 0}$ in the visible region at around $750 \mathrm{~nm}$ gradually developed, along with decrement of the absorption band at around $550 \mathrm{~nm}$. Reverse oxidation decreased the new absorption bands and regenerated the absorption band of 20 (Figure S-78).

Visible spectra of tris-AzTCBDs 21-24 were exhibited similar reversible color change corresponded to those of AzTCBD 17-20, although the absorption coefficients of 21-24 were increased (see the Supporting Information). These results also support the idea that central benzene ring substituted by three azulene rings shield the intramolecular interaction among the substituted TCBD units.

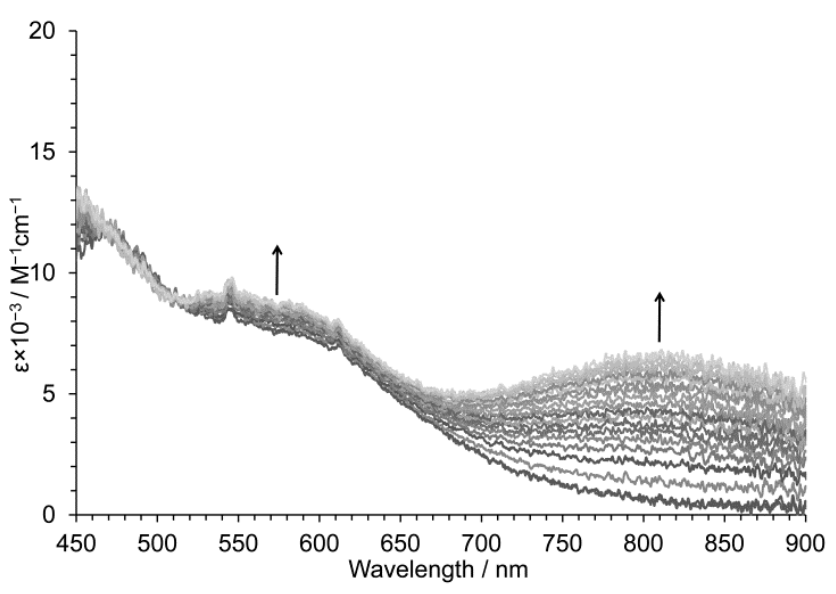




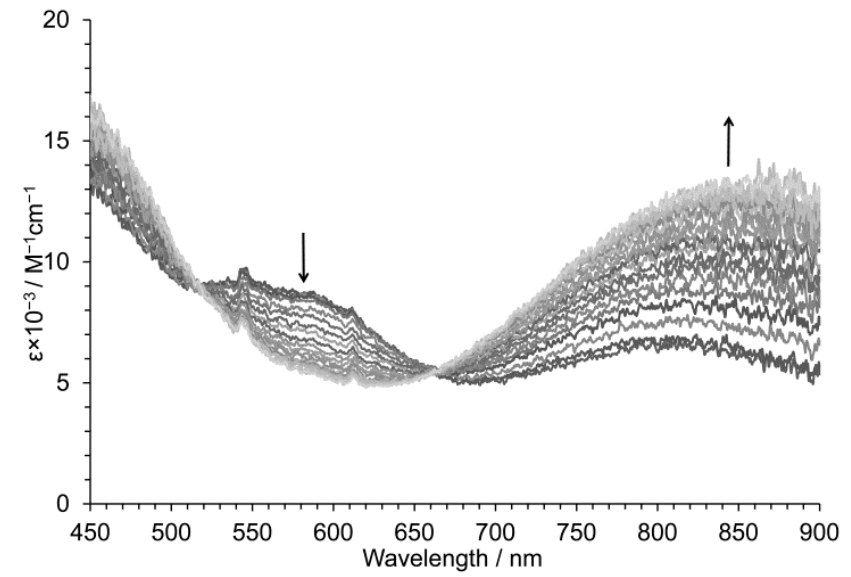

Figure 4. Continuous change in the UV/Vis spectrum of 19: constant-voltage electrochemical reduction at $-0.75 \mathrm{~V}$ (top), further electrochemical reduction at $-1.20 \mathrm{~V}$ (bottom)

\section{Conclusions}

A series of alkynes 5-7 and 10, and tris-alkynes 13-16 with aryl groups at the periphery were prepared by $\mathrm{Pd}$-catalyzed Sonogashira-Hagihara reaction. AzTCBDs 17-20 and tris-AzTCBDs 21-24 were synthesized in a one-step procedure consisting of formal [2 + 2] CA-RE reaction of the corresponding alkynes with TCNE. Intramolecular CT absorption bands of the new TCBD derivatives were clarified by UV/vis spectra and theoretical calculations. Analyses by CV and DPV showed that the AzTCBDs 17-20 and tris-AzTCBDs 21-24 exhibited reversible two-stage reduction waves, in which the first reduction potentials were depended on the substituted aryl groups, although the AzTCBDs and the corresponding tris-AzTCBDs showed almost the same reduction potentials. These results revealed that the little electronic interaction between the three TCBD moieties of the tris-AzTCBDs 21-24 on benzene ring, although the aryl groups on TCBD group were directly affected by nature of compounds. Significant color and spectral changes of the AzTCBDs 17-20 and tris-AzTCBDs 21-24 were observed during the electrochemical reduction conditions. Especially, AzTCBD 19 and tris-AzTCBD 23 with p-nitrophenyl substitutes exhibited reversible two-stage color changes, attributable to the stable anionic species generated by electrochemical reduction.

These results obtained by this study should contribute to the creation of electronic devices utilizing AzTCBD derivatives.

\section{Acknowledgements}

This work was supported by JSPS KAKENHI Grant Number 25810019, Grant-in-Aid for Young Scientists (B), to T.S.

Keywords: Azulene - Donor-acceptor chromophores • Cycloaddition $\cdot$ UV/Vis spectrum $\cdot$ Redox chemistry
[1] a) J. L. Brédas, C. Adant, P. Tackx, A. Persoons, B. M. Pierce, Chem. Rev. 1994, 94, 243-278; b) M. Bendikov, F. Wudl, D. F. Perepichka, Chem. Rev. 2004, 104, 4891-4945; c) S. Hünig, E. Herberth, Chem. Rev. 2004, 104, 5535-5563; d) T. Baumgartner, R. Réau, Chem. Rev. 2006, 106, 4681-4727; e) G. Clavier, P. Audebert, Chem. Rev. 2010, 110, 3299-3314.

[2] a) T. Michinobu, I. Boudon, J.-P. Gisselbrecht, P. Seiler, B. Frank, N. N P. Moonen, M. Gross, F. Diederich, Chem. Eur. J. 2006, 12, 1889-1905 b) F. Tancini, F. Monti, K. Howes, A. Belbakra, A. Listorti, W. B Schweizer, P. Reutenauer, J.-L. Alonso-Gómez, C. Chiorboli, L. M Urner, J.-P. Gisselbrecht, C. Boudon, N. Armaroli, F. Diederich, Chem Eur. J. 2014, 20, 202-216; c) G. Jayamurugan, A. D. Finke, J.-P Gisselbrecht, C. Boudon, W. B. Schweizer, F. Diederich, J. Org. Chem. 2014, 79, 426-431.

[3] a) M. Kivala, C. Boudon, J.-P. Gisselbrecht, P. Seiler, M. Gross, F. Diederich, Chem. Commun. 2007, 4731-4733; b) M. Kivala, C. Boudon, J.-P. Gisselbrecht, B. Enko, P. Seiler, I. B. Müller, N. Langer, P. D. Jarowski, G. Gescheidt, F. Diederich, Chem. Eur. J. 2009, 15, 41114123; c) S.-i. Kato, M. Kivala, W. B. Schweizer, C. Boudon, J.-P. Gisselbrecht, F. Diederich, Chem. Eur. J. 2009, 15, 8687-8691.

[4] a) B. Esembeson, M. L. Scimeca, T. Michinobu, F. Diederich, I. Biaggio, Adv. Mater. 2008, 20, 4584-4587; b) C. Koos, P. Vorreau, T. Vallaitis, P. Dumon, W. Bogaerts, R. Baets, B. Esembeson, I. Biaggio, T. Michinobu, F. Diederich, W. Freude, J. Leuthold, Nat. Photonics 2009, 3, 216-219.

[5] a) T. Michinobu, Pure Appl. Chem. 2010, 82, 1001-1009; b) Y. Yuan, T. Michinobu, J. Oguma, T. Kato, K. Miyake, Macromol. Chem. Phys. 2013, 214, 465-1472.

[6] T. Michinobu, C. Seo, K. Noguchi, T. Mori, Polym. Chem. 2012, 3, 1427-1435

[7] Y. Li, M. Ashizawa, S. Uchida, T. Michinobu, Macromol. Rapid Commun 2011, 32, 1804-1808; b) T. Michinobu, Y. Li, T. Hyakutake, Phys. Chem. Chem. Phys. 2013, 15, 2623-2631.

[8] a) T. Shoji, S. Ito, K. Toyota, M. Yasunami, N. Morita, Chem. Eur. J. 2008, 14, 8398-8408; b) T. Shoji, M. Maruyama, S. Ito, N. Morita, Bull. Chem. Soc. Jpn. 2012, 85, 761-773; c) T. Shoji, S. Ito, T. Okujima, N Morita, Org. Biomol. Chem. 2012, 10, 8308-8313; d) T. Shoji, S. Ito, T. Okujima, N. Morita, Chem. Eur. J. 2013, 19, 5721-5730; e) T. Shoji, M. Maruyama, A. Maruyama, S. Ito, T. Okujima, K. Toyota, Chem. Eur. J. 2014, 20, 11903-11912.

[9] a) T. Shoji, S. Ito, K. Toyota, T. Iwamoto, M. Yasunami, N. Morita, Eur. J. Org. Chem. 2009, 4316-4324; b) T. Shoji, E. Shimomura, M. Maruyama, A. Maruyama, S. Ito, T. Okujima, K. Toyota, N. Morita, Eur. J. Org. Chem. 2013, 7785-7799; c) T. Shoji, M. Maruyama, E. Shimomura, A. Maruyama, S. Ito, T Okujima, K. Toyota, N. Morita, J. Org. Chem. 2013, 78, 12513-12524.

[10] T. Shoji, A. Maruyama, E. Shimomura, D. Nagai, S. Ito, T. Okujima, K. Toyota, Eur. J. Org. Chem. 2015, 1979-1990.

[11] a) P. W. Yang, M. Yasunami, K. Takase, Tetrahedron Lett. 1971, 4275-4278; b) M. Yasunami, A. Chen, P. W. Yang, K. Takase, Chem Lett. 1980, 9, 579-582; c) M. Yasunami, A. Chen, Y. Noro, K. Takase, Chem. Lett. 1981, 10, 555-558.

[12] Successful iodation by the addition of triethylamine was also reported in the reaction of 2-aminoazulene derivative with NIS. M. Hyoudou, $\mathrm{H}$. Nakagawa, T. Gunji, Y. Ito, Y. Kawai, R. Ikeda, T. Konakahara, N. Abe, Heterocycles 2012, 86, 233-244.

[13] $\mathrm{CH}_{2} \mathrm{Cl}_{2}$ was included to maintain the solubility of compound 9 .

[14] The B3LYP/6-31G** time-dependence density functional calculations were performed with Spartan'10, Wavefunction, Irvine, CA.

[15] The voltammetry measurements were performed with a BAS 100B/W electrochemical workstation equipped and with a standard three electrode configuration and all measurements were carried out under an argon atmosphere. Tetraethylammonium perchlorate $(0.10 \mathrm{M})$ in benzonitrile was used as a supporting electrolyte, with a platinum wire auxiliary and disk working electrodes. Reference electrode was formed from $\mathrm{Ag} / \mathrm{AgNO}_{3}(0.01 \mathrm{M})$ in acetonitrile containing tetrabutylammonium 
perchlorate $(0.10 \mathrm{M})$. The half-wave potential of the ferrocene/ferrocenium ion couple $\left(\mathrm{Fc} / \mathrm{Fc}^{+}\right)$under these conditions using this reference electrode was observed at $+0.15 \mathrm{~V}$ on CV. Accuracy of the reference electrode was confirmed by $\mathrm{CV}$ measurements of the couple in each sample as an internal ferrocene standard.

[16] G. Jayamurugan, O. Dumele, J.-P. Gisselbrecht, C. Boudon, W. B. Schweizer, B. Bernet, F. Diederich, J. Am. Chem. Soc. 2013, 135 3599-3606. 


\section{Entry for the Table of Contents}

\section{FULL PAPER}

1-Azulenylaryltetracyanobetadienes and Tris(aryltetracyanobetadiene)s connected to

a

1,3,5-tri(1-azulenyl)benzene core were prepared by the formal [2 + 2] cycloaddition-

retroelectrocyclization of TCNE with the corresponding alkynes. The spectral study and redox behavior of the TCBD derivatives was examined by CV, DPV, and spectroelectrochemistry.

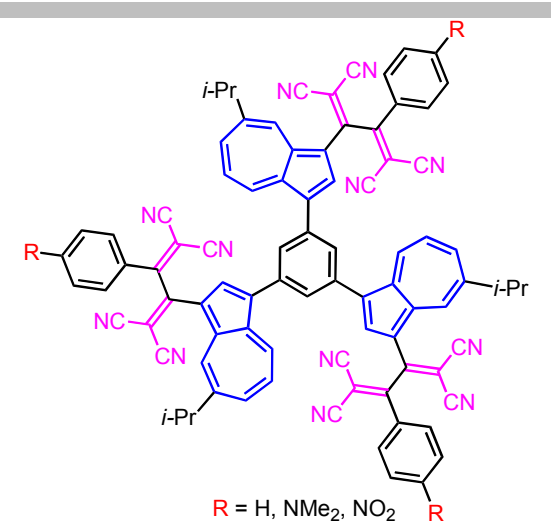

Taku Shoji, * Akifumi Maruyama, Miwa Tanaka, Daichi Nagai, Erika Shimomura, Kunihide Fujimori, Shunji Ito, Tetsuo Okujima, Kozo Toyota, and Masafumi Yasunami

Page No. - Page No.

Synthesis and Properties of (3-phenyl-1-azulenyl)tetracyanobetadienes and Tris(aryltetracyanobetadiene)s

Connected with

1,3,5-Tri(1-azulenyl)benzene Core 